\title{
Minimally invasive veneers: current state of the art
}

This article was published in the following Dove Press journal:

Clinical, Cosmetic and Investigational Dentistry

28 November 2014

Number of times this article has been viewed

\section{Burçin Akoğlu Vanlıoğlu Yasemin Kulak-Özkan}

University of Marmara, Department of Prosthetic Dentistry, Istanbul, Turkey
Correspondence: Burçin Akoğlu Vanlıŏlu

University of Marmara, Department of Prosthodontics, Büyükçiftlik Sokak, No 6, Güzelbahçe, 34365, Nișantașı, Istanbul, Turkey Fax +90 2I 22465247

Email drburcinakoglu@hotmail.com
Abstract: Ceramic veneers are considered a conservative solution for patients requiring improvement of the shape, color, or position of their anterior teeth. Ceramic veneers have been extensively and successfully used to mask intrinsic staining, to give the appearance of straightening, and to correct minor malformations of anterior teeth without the removal of substantial amounts of sound tooth substance. The current literature was reviewed to search for the most important parameters determining the long-term success and correct application of ceramic veneers.

Keywords: ceramic veneers, esthetic treatment

\section{Introduction}

Ceramic veneers (CVs), which are chosen to provide excellent esthetics, are a wellestablished treatment method for conservative esthetic restoration of malformed, discolored, misaligned, traumatized, fractured, and worn anterior teeth. The recommended superficial preparation within the enamel and adhesive luting facilitates restoration with minimal loss of healthy tooth structure. ${ }^{1}$

Magne and Belser ${ }^{2}$ presented the following classification for indications for ceramic veneers:

- Type I: Teeth resistant to bleaching

o Type IA: Tetracycline discoloration

o Type IB: Teeth that are unresponsive to bleaching

- Type II: Major morphologic modifications

o Type IIA: Conoid teeth

o Type IIB: Diastema or interdental triangles to be closed

o Type IIC: Augmentation of incisal length or facial prominence

- Type III: Extensive restorations

o Type IIIA: Extensive coronal fracture

o Type IIIB: Extensive loss of enamel by erosion and wear

o Type IIIC: Generalized congenital malformations.

Within this classification system, the use of minimal-preparation and nopreparation CVs can achieve the desired esthetic outcome in a conservative manner for Types I and II.

Initially, CVs were fabricated from stacked feldspathic porcelain and used in a "no-prep" manner in 0.5-0.7 mm thickness. ${ }^{3}$ Although not removing healthy tooth structure was admirable, it often provided less-than-desirable results. The veneers 
often appeared bulky, and the soft tissue would show signs of irritation. It is important to remember that the ultimate objective of any dental treatment is to restore health and function, as well as esthetics, using the most conservative method of treatment available.

Recent marketing efforts by dental manufacturers and laboratories, directed both at dentists and consumers, have advocated "no-preparation" veneers as a tooth structureconserving option that is esthetically equivalent to or better than veneers requiring preparation. The final desired position, color, and shape of the restoration should be the main determinants of the level of reduction. There are many significant advantages of conservation of tooth structure, including lack of need for anesthesia, absence of postoperative sensitivity, bonding to enamel, minimal flexing stress, longer-lasting restorations, potential for reversal, and higher levels of acceptance of treatment among patients. ${ }^{4,5}$ Patients with small or lingually positioned teeth should be considered ideal candidates for techniques involving no or minimal preparation.

As PLVs continued to evolve, a minimally invasive approach was used to provide a more esthetic and biologically compatible restoration. A minimal preparation of $0.5 \mathrm{~mm}$ was used to allow a place for veneers, be able to adequately mask unesthetic areas, and/or change the color, as well as provide the minimal strength needed for the fabrication and delivery of the PLV. ${ }^{6,7}$

Edelhoff and Sorensen ${ }^{8}$ reported that tooth preparations for CVs required 3\%-30\% of tooth structure by weight and one-quarter to one-half the amount of tooth reduction of conventional complete-coverage crowns. This article is intended to give rational guidelines on preparation parameters for CVs, particularly the issue of how to prepare and how not to prepare.

\section{Incisal preparation}

Different designs of tooth preparations have been described as the feathered incisal edge, the incisal $0.5-1 \mathrm{~mm}$ bevel, the intraenamel (or window), and the overlapped incisal edge preparations. There are different reports as to whether the incisal edge should be included in the preparation for CVs. Castelnuovo et $\mathrm{al}^{9}$ reported that elimination of the palatal chamfer for CVs with incisal butt joints resulted in stronger restorations and simplified tooth preparation. They also suggested that the faciopalatal path of insertion allowed easier seating of multiple veneers and eliminated the risk for fracture of thin, unsupported palatal ceramic ledges. Akoğlu and Gemalmaz ${ }^{10}$ evaluated the fracture load and the mode of failure of CVs with preparations on either enamel or dentin. They reported that CVs with preparation designs entirely on dentin with $4 \mathrm{~mm}$ incisal reduction yielded lower fracture loads than those prepared with $2 \mathrm{~mm}$ incisal reduction, and veneers with $2 \mathrm{~mm}$ incisal reduction exhibited fracture resistance similar to that of intact teeth for preparation designs supplied on both enamel and dentin. The present trend when teeth are prepared for $\mathrm{CVs}$ is to include the incisal edge either by beveling or by means of overlapping. A silicone index is more helpful than a depth gauge bur when preparing the palatal surface and reducing the incisal edge, with a depth gauge bur having limited application in this situation. ${ }^{11}$

\section{Labial preparation}

There are several methods of attaining the reduction required with the preparation: freehand, use of depth cuts/grooves (the use of depth cutters or grooves and dimples has been recommended to control tooth preparation, as the use of standardized objects allows accurate judgment of depth), and use of silicone putty index or the provisional (use of a silicone index derived from the wax-up allows a visualization of the reduction required to achieve the form and contours of the preplanned shape and length of the final veneers).

Many studies suggest a $0.5 \mathrm{~mm}$ minimal thickness for tooth preparations for CVs. According to Nattress et al, ${ }^{12}$ freehand preparation can result in variable depth of preparation with dentin exposure. Ferrari et al ${ }^{13}$ sectioned and measured the thickness of the labial enamel of 114 extracted incisor and premolar teeth at three sites, the gingival third, the middle third, and incisal third, with the results indicating that enamel thickness at the gingival third was $0.3-0.4 \mathrm{~mm}$ for incisor teeth. The authors argued that because the enamel should be reduced by $0.5 \mathrm{~mm}$ in a veneer preparation, this would result in dentin being exposed at the gingival margin, or alternatively, if the teeth are reduced less, an overcontoured restoration could result. Inadequate labial reduction can potentially lead to increased bulk in the veneer, whereas overreduction needlessly results in more extensive dentine exposure. ${ }^{14-16}$ In cases in which the operator fails to achieve uniform reduction of the labial surface, taking account of the facial contours of the tooth, it is common to find areas of both inadequate and unnecessarily extensive reduction within the same preparation. Given the tendency to underprepare when teeth are prepared freehand, it is recommended that either an index or appropriate depth gauge bur be used when teeth are prepared for CVs. Some freehand preparation of severely discolored teeth will still be required, so as to ensure a successful esthetic outcome, with an increased thickness 
of porcelain and/or luting cement in the final restoration having a greater masking ability. ${ }^{17}$ Experienced, skilled ceramists have been able to create PLVs that are $0.3 \mathrm{~mm}$ thick. This ability has now allowed many dentists to become even more conservative in their preparation of teeth for PLV. In addition, Wells ${ }^{7}$ has demonstrated that in certain situations, it is possible to place no-prep veneers while achieving the desired esthetic results without compromising function or soft tissue health.

The idea of minimally invasive dental restorations is essential for successful restorations. In these restorations, an appropriate restorative planning must be conducted. Minimum-thickness ceramic laminate veneers have been increasingly indicated. The dentist and laboratory technician must follow a proper protocol to achieve higher clinical success rates. It is important to emphasize that the clinician should have a good understanding of the ceramic type to establish the appropriate cementation procedure that will contribute to long-lasting restorations. When CVs are considered, different restorative approaches have been proposed, depending on the thickness of the veneer and the color of the remaining dental structure. In the case of improving esthetics by changing the form and texture of teeth with no severe discoloration, veneers of smaller thickness may be indicated. ${ }^{2,11}$ Minimally invasive preparation for PLVs is a highly conservative treatment and is indicated for small corrections of the incisal edge, dental fractures, conoid teeth, and diastemas. It requires $0.1 \mathrm{~mm}$ reduction at the cervical third, $0.2-0.5 \mathrm{~mm}$ reduction in the middle third, and $0.7-1.0 \mathrm{~mm}$ reduction in the incisal third. If the desired esthetic change is not in tooth form but only in color, it may not be necessary to overlap the incisal edge, particularly if there is sufficient buccolingual width. However, if it is desired to increase the length of the crown, it is important to overlap the incisal edge.

\section{Interproximal extension}

There is no conclusive evidence that can be found for what is the best way to prepare the interproximal area of a tooth for a CV. Options range from virtually no preparation to a preparation that stops just short of the interproximal contact to a slight opening of the interproximal contact. ${ }^{6}$ Breaking the contact (sometimes called the "slice preparation") may be necessary to clear the contact in certain situations, such as changing the shape or position of teeth and in the case of multiple veneers. With the additional space interproximally, this allows the ceramist freedom to adjust the contours and position of the teeth. ${ }^{2}$

\section{Cervical margin}

The desired position for the finish line of the veneer is just within the confines of the gingival sulcus. There is no reason to hide the interface subgingivally unless a very dramatic color change is desired. The configuration of the finish line should be chamfer. ${ }^{2}$ From the laboratory perspective, it is extremely beneficial for the dentist to place at least a light chamfer finish line so that the ceramist clearly knows where to build the porcelain. In tetracycline-stained cases, it is desirable to go further subgingivally to mask the dark staining in the cervical region. In this situation, it may also be necessary to remove slightly more tooth structure. Conventional diamond burs leave a macroscopically roughened surface on enamel. Further preparation of the tooth using either a small particle size diamond bur or a multifluted tungsten carbide finishing bur will smooth the surface of the preparation and can be used to refine the finishing margin. ${ }^{2,6}$

Preparation for CVs should be made meticulously to maintain the preparation completely in enamel. However, exposure of considerable amounts of dentine is usually inevitable during the preparation, especially along the cervical and proximal areas. ${ }^{13}$ Although improved new adhesives are developed, the bond strength of porcelain to enamel is still superior compared with the bond strength of porcelain to dentine. ${ }^{1-3,6}$

\section{Clinical success keys}

Calamia and Calamia ${ }^{3}$ have suggested that success of the $\mathrm{CV}$ technique involves the paying of great attention to detail for the following: planning the case, conservative (enamelsaving) preparation of teeth, proper selection of ceramics, proper selection of the materials and methods of cementation, proper finishing and polishing of the restorations, and proper planning for the continued maintenance of the restorations.

\section{Material selection}

To improve esthetics in anterior teeth by means of laminate veneers, two types of materials are indicated for their translucency and potential to be used in small thickness: sintered feldspathic porcelain and pressable ceramic, which can also be milled using a computer-aided manufacturing technique. $^{18}$

Type I patients are candidates for conventional ceramics, whereas type II patients require high-resistance ceramics. Type IB patients require simple esthetic facets, although in this case the substrate teeth present color alterations. Therefore, independent of the need for shape modifications, the selected ceramic material must be able to hide the underlying 


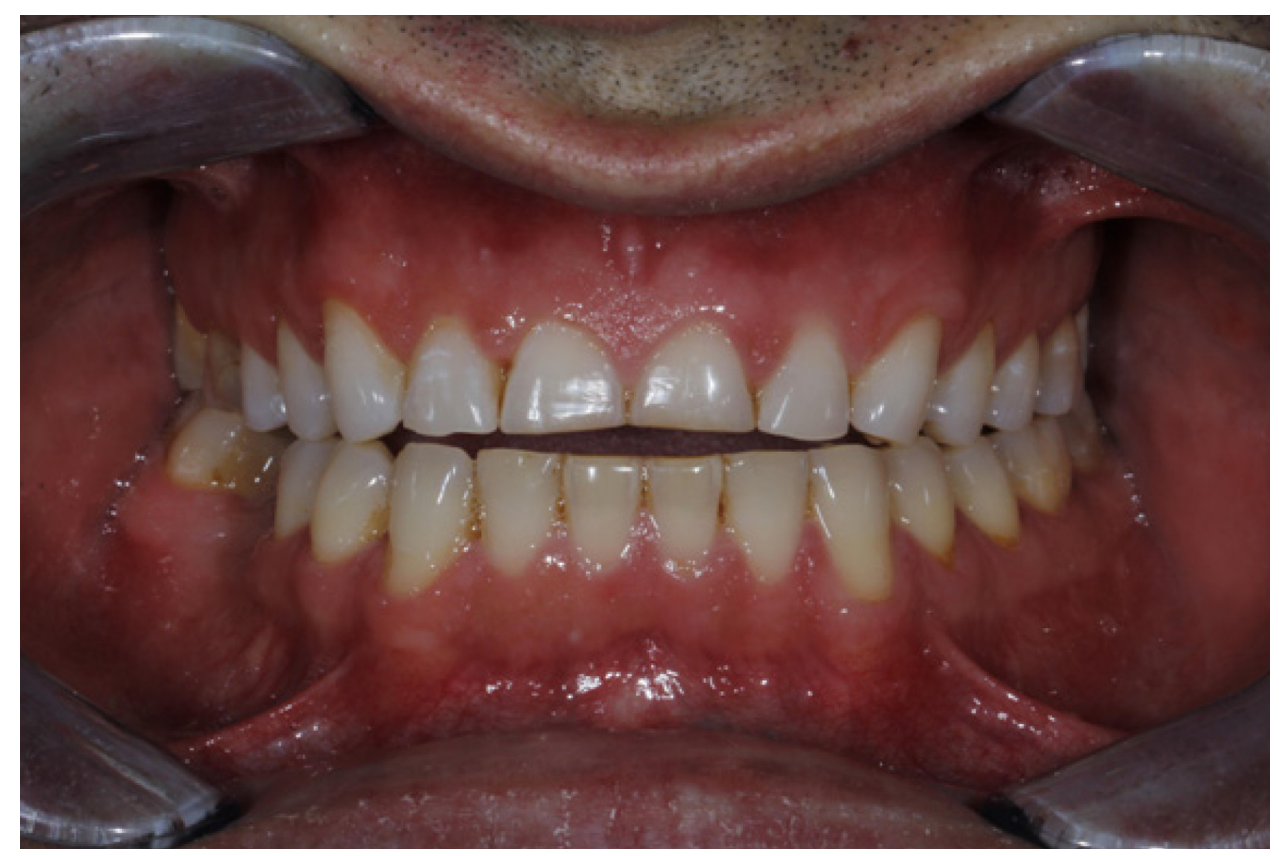

Figure I Intraoral view of the patient with worn anterior dentition as a result of bruxism.

substrate color. In these cases, both the porcelain and cement must present various degrees of opacity to hide the color alterations. In Type II patients, feldspate or alumina ceramics of high resistance, and oxide ceramics are indicated. ${ }^{18}$

\section{Cementation}

There are many systems that have color-corrected, watersoluble try-in gels; optimal viscosity levels; and color-stable resin cements, opaques, and color modifiers. Once properly cemented, CVs become an integral part of the tooth structure and share part of applied loading stresses during the masticatory cycle. For cementation of CVs, a light-curing luting composite is preferred. In the case of ceramic with a thickness of more than $0.7 \mathrm{~mm}$, light-cured resin composites do not reach their maximum hardness. In these situations, a dual-cured luting composite is advisable., ${ }^{1,2}$

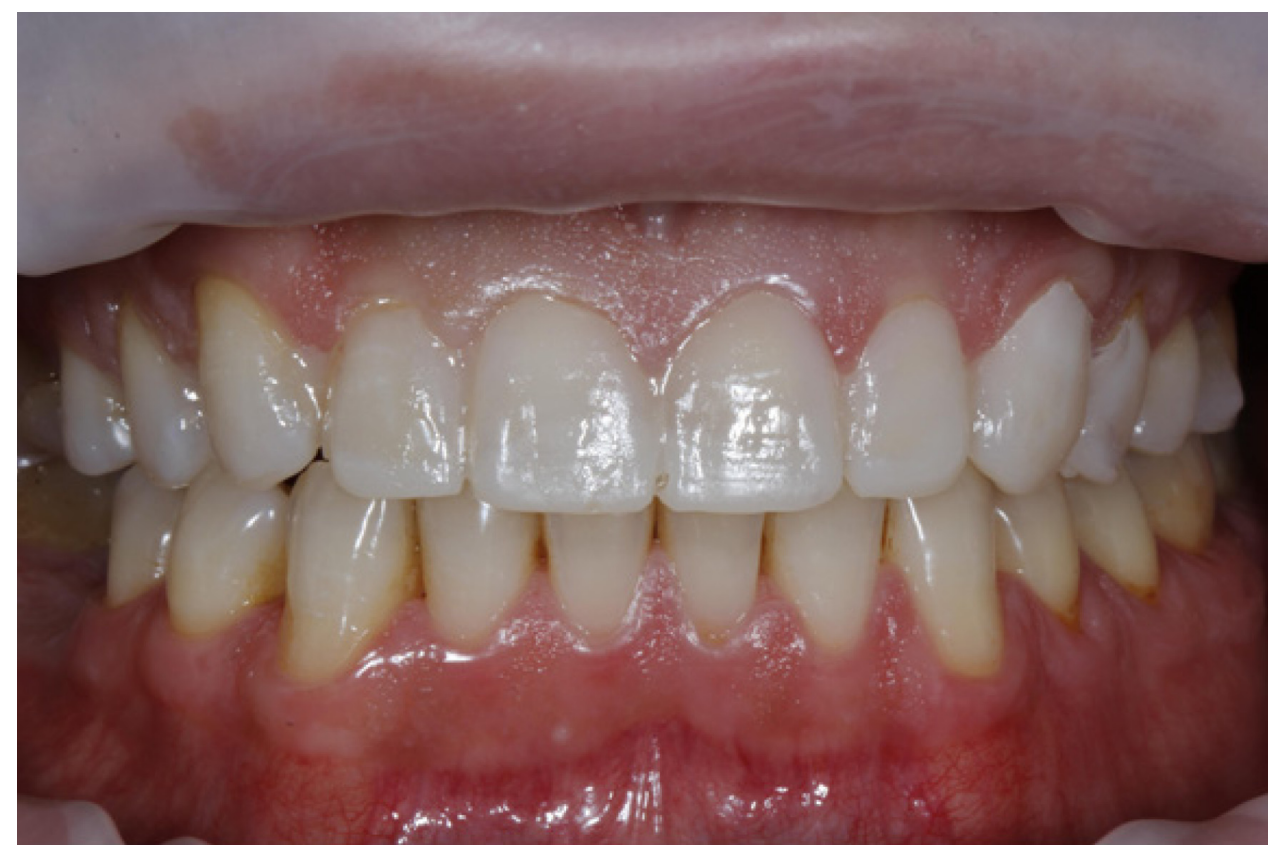

Figure 2 Diagnostic preevaluative temporary restorations are used to evaluate the prosthetic outcome. 


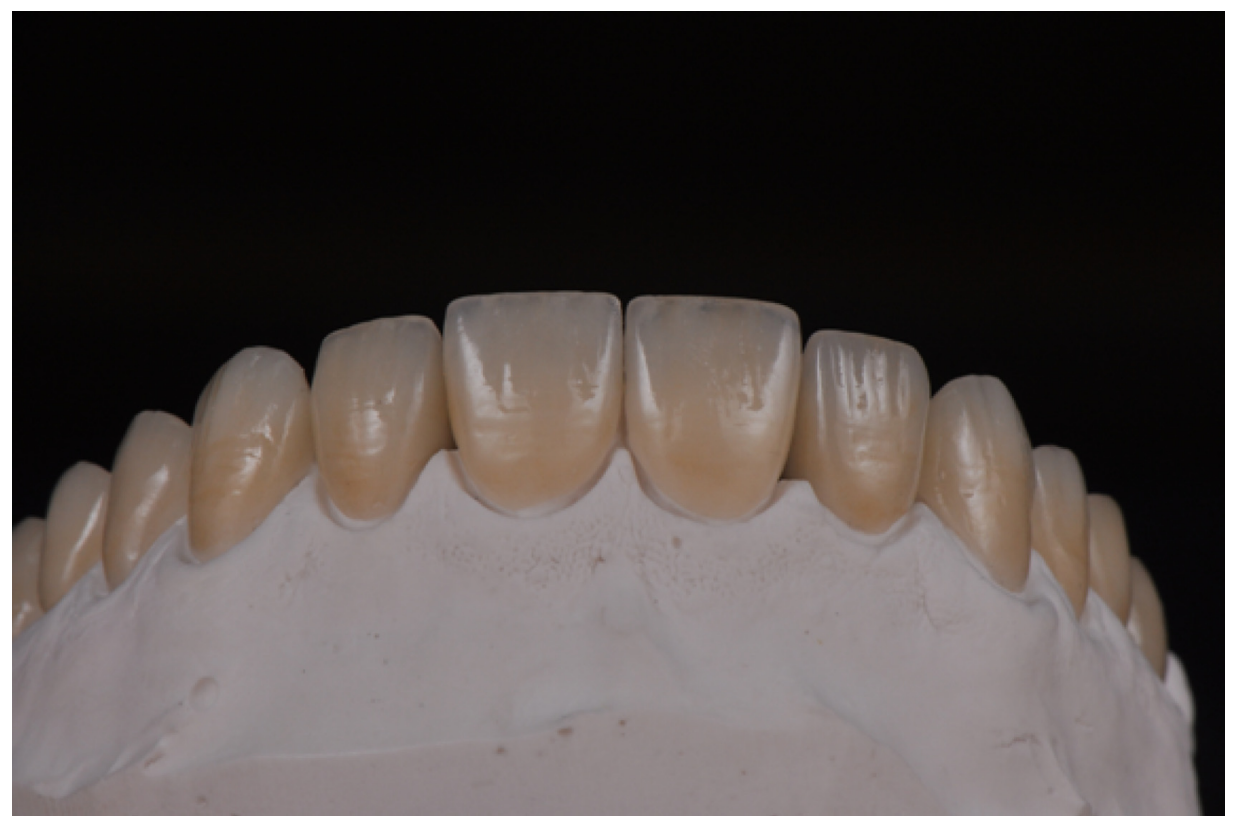

Figure 3 Ceramic veneers on the stone model.

The success of the porcelain veneer is greatly determined by the strength and durability of the bond formed between the three different components of the bonded veneer complex: the tooth surface, the porcelain veneer, and the luting composite. Magnification can be preferred for cementation procedures. The veneers should be evaluated on the laboratory model for proper seating and marginal adaptation. A rubber dam is critical on mandibular teeth to isolate the lip and tongue and to control moisture.

\section{Clinical studies}

The success rate of CVs has been clinically evaluated and has shown a range from 18 months up to 20 years; the rate of success reported in these studies varies between $75 \%$ and $100 \%{ }^{19-29}$ Fracture, microleakage, and debonding are types of failures seen in CVs. Burke ${ }^{30}$ reported that survival rates of CVs are rarely $100 \%$, and there is reasonable evidence indicating that a veneer preparation into dentin adversely affects survival.

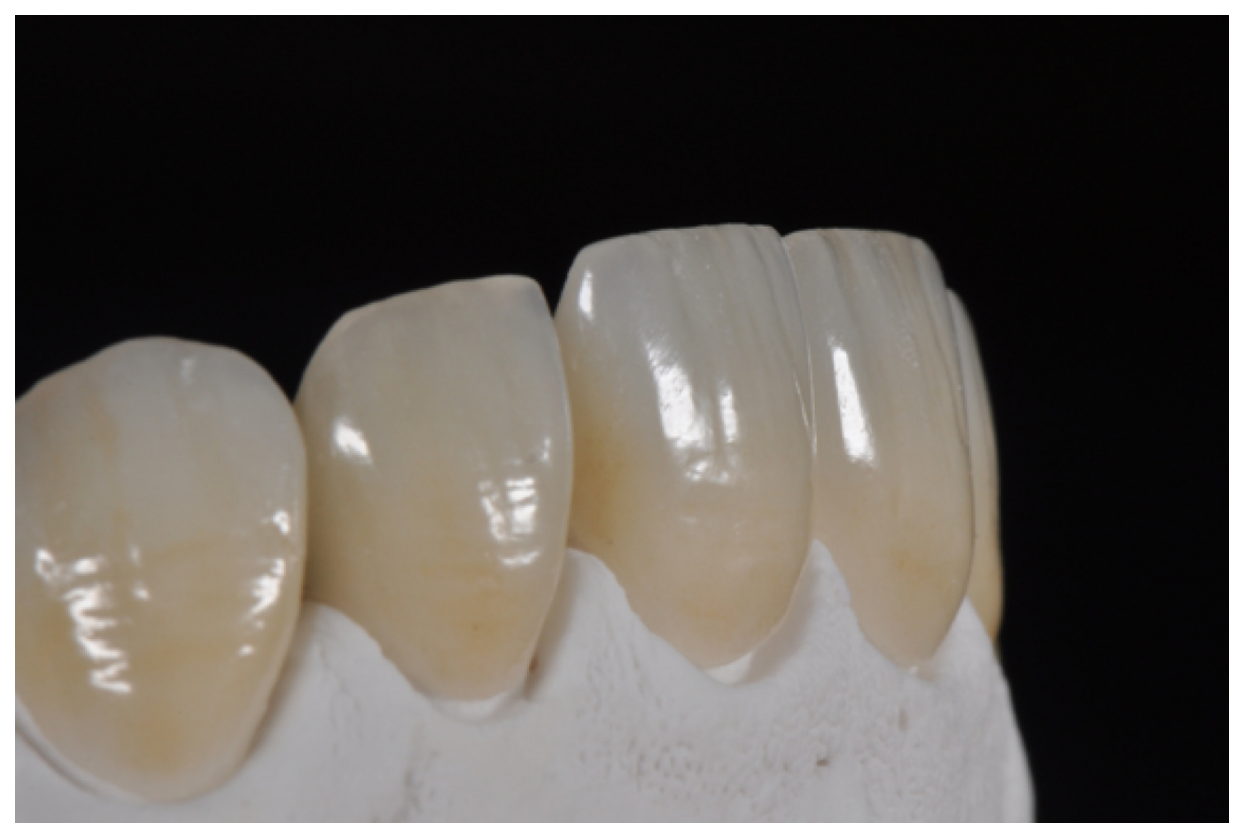

Figure 4 Lateral view of the ceramic veneers. 


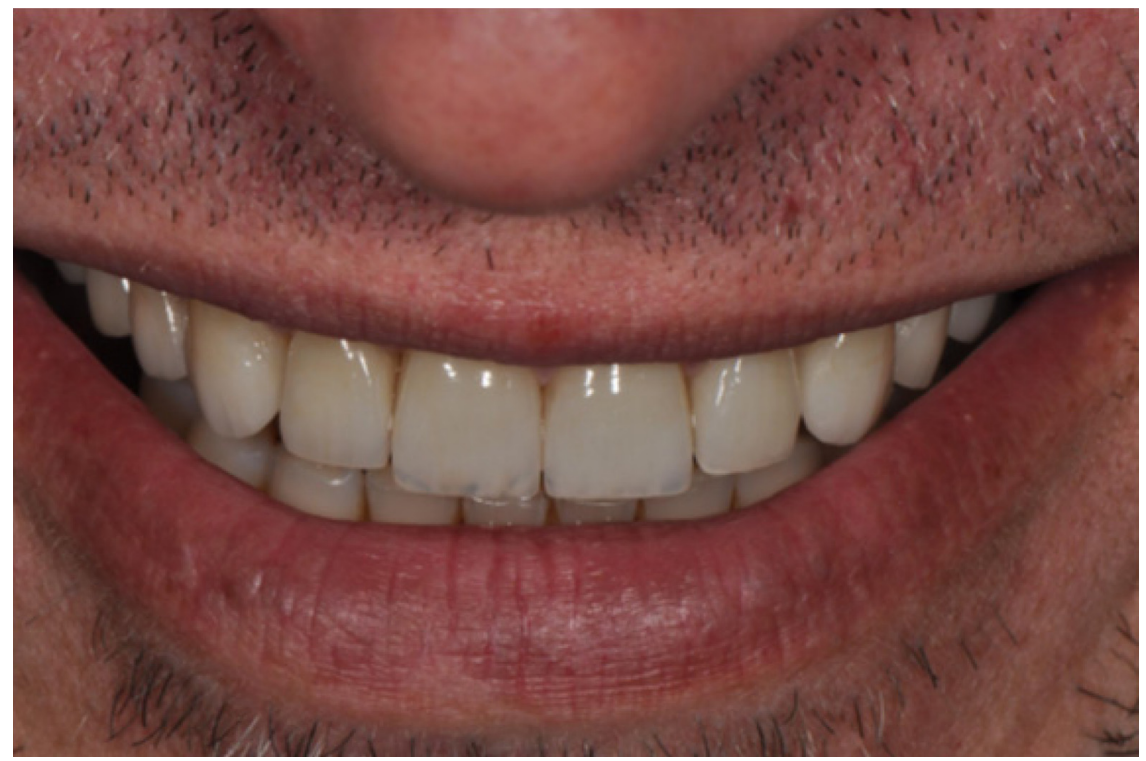

Figure 5 Extraoral view of the patient with the new smile line.

The preparation of the teeth greatly influences the durability and color (translucency and tonality) of the ceramic restoration, as the tooth preparation will determine the inner superficial contour and the thickness of the ceramic material. ${ }^{18}$ A veneer requires a minimum of $0.2 \mathrm{~mm}$ to (ideally) $0.3 \mathrm{~mm}$ of thickness for each shade change. ${ }^{31}$ Ceramic translucency also plays an important role for light penetration.

Patients with bruxism or tooth-to-foreign object contact may not be ideal candidates for veneers. In cases of minor incisal wear owing to bruxism, it is often possible to restore the incisal length using PLVs. It is very important to evaluate the occlusal scheme and manage the occlusal forces before any treatment with PLVs is attempted. In these cases, an occlusal guard is indicated to assist in the prevention of postoperative ceramic fracture (Figures 1-5).

\section{Conclusion}

The minimum-thickness anterior ceramic laminate veneers may be a conservative and esthetic alternative to reestablish the form, shape, and color of anterior teeth. Even though it is one of the most conservative of treatment options, some rules have to be followed. The case has to be carefully selected and treatment planned. Tooth reduction for any restorative technique should be as conservative as possible, especially for CVs. No-preparation veneers are indicated for selected cases only, and a larger number of cases require some kind of tooth modification for superior esthetics, patient satisfaction, and better color change without affecting the thickness and emergence profile of the veneer.

\section{Disclosure}

The authors report no conflicts of interest in this work.

\section{References}

1. Peumans M, Van Meerbeek B, Lambrechts P, Vanherle G. Porcelain veneers: a review of the literature. J Dent. 2000;28(3):163-177.

2. Magne P, Belser UC. Bonded Porcelain Restorations in the Anterior Dentition-a Biomimetic Approach. Chicago: Quintessence Publishing Co; 2002.

3. Calamia JR, Calamia CS. Porcelain laminate veneers: reasons for 25 years of success. Dent Clin North Am. 2007;51(2):399-417, ix.

4. Malcmacher L. No-preparation porcelain veneers - back to the future! Dent Today. 2005;24(3):86, 88, 90-91.

5. Javaheri D. Considerations for planning esthetic treatment with veneers involving no or minimal preparation. J Am Dent Assoc. 2007;138(3): 331-337.

6. Radz GM. Minimum thickness anterior porcelain restorations. Dent Clin North Am. 2011;55(2):353-370, ix.

7. Wells DJ. "No-prep" veneers. Inside Dent. 2010;6(8):56-60.

8. Edelhoff D, Sorensen JA. Tooth structure removal associated with various preparation designs for anterior teeth. J Prosthet Dent. 2002;87(5): 503-509.

9. Castelnuovo J, Tjan AHL, Phillips K, Nicholls JI, Kois JC. Fracture load and mode of failure of ceramic veneers with different preparations. J Prosthet Dent. 2000;83(2):171-180.

10. Akoğlu B, Gemalmaz D. Fracture resistance of ceramic veneers with different preparation designs. J Prosthodont. 2011;20(5):380-384.

11. Brunton PA, Aminian A, Wilson NH. Tooth preparation techniques for porcelain laminate veneers. Br Dent J. 2000;189(5):260-262.

12. Nattress BR, Youngson CC, Patterson CJ, Martin DM, Ralph JP. An in vitro assessment of tooth preparation for porcelain veneer restorations. J Dent. 1995;23(3):165-170.

13. Ferrari M, Patroni S, Balleri P. Measurement of enamel thickness in relation to reduction for etched laminate veneers. Int $J$ Periodontics Restorative Dent. 1992;12(5):407-413.

14. Parmeijer CH. Porcelain laminate veneers. J Calif Dent Assoc. 1991; 19(4):59-62.

15. Weinberg LA. Tooth preparation for porcelain laminates. $N Y$ State Dent J. 1989;55(5):25-28. 
16. Clyde JS, Gilmour A. Porcelain veneers: a preliminary review. Br Dent J. 1988;164(1):9-14.

17. Chen JH, Shi CX, Wang M, Zhao SJ, Wang H. Clinical evaluation of 546 tetracycline-stained teeth treated with porcelain laminate veneers. J Dent. 2005;33(1):3-8.

18. Pini NP, Aguiar FH, Lima DA, Lovadino JR, Terada RS, Pascotto RC Advances in dental veneers: materials, applications, and techniques. Clin Cosmet Investig Dent. 2012;4:9-16.

19. Strassler HE, Weiner S. Seven to ten-year clinical evaluation of porcelain laminate veneers. J Dent Res. 1995;74:176.

20. Walls AWG. The use of adhesively retained all-porcelain veneers during the management of fractured and worn anterior teeth: Part 2. Clinical results after 5 years of follow-up. Br Dent $J$. 1995;178(9):337-340.

21. Dumfahrt H. Porcelain laminate veneers. A retrospective evaluation after 1 to 10 years of service: Part I - Clinical procedure. Int $J$ Prosthodont. 1999;12(6):505-513.

22. Aristidis GA, Dimitra B. Five-year clinical performance of porcelain laminate veneers. Quintessence Int. 2002;33(3):185-189.

23. Peumans M, De Munck J, Fieuws S, Lambrechts P, Vanherle G, Van Meerbeek B. A prospective ten-year clinical trial of porcelain veneers. J Adhes Dent. 2004;6(1):65-76.

24. Gurel G, Sesma N, Calamita MA, Coachman C, Morimoto S. Influence of enamel preservation on failure rates of porcelain laminate veneers. Int J Periodontics Restorative Dent. 2013;33(1):31-39.
25. Gurel G, Morimoto S, Calamita MA, Coachman C, Sesma N. Clinical performance of porcelain laminate veneers: outcomes of the aesthetic pre-evaluative temporary (APT) technique. Int $J$ Periodontics Restorative Dent. 2012;32(6):625-635.

26. Beier US, Kapferer I, Burtscher D, Dumfahrt H. Clinical performance of porcelain laminate veneers for up to 20 years. Int J Prosthodont. 2012;25(1):79-85

27. D'Arcangelo C, De Angelis F, Vadini M, D'Amario M. Clinical evaluation on porcelain laminate veneers bonded with light-cured composite: results up to 7 years. Clin Oral Investig. 2012;16(4):1071-1079.

28. Shetty A, Kaiwar A, Shubhashini N, et al. Survival rates of porcelain laminate restoration based on different incisal preparation designs: An analysis. J Conserv Dent. 2011;14(1):10-15.

29. Fradeani M. Six-year follow-up with Empress veneers. Int J Periodontics Restorative Dent. 1998;18(3):216-225.

30. Burke FJ. Survival rates for porcelain laminate veneers with special reference to the effect of preparation in dentin: a literature review. $J$ Esthet Restor Dent. 2012;24(4):257-265.

31. McLaren EA, LeSage B. Feldspathic veneers: what are their indications? Compend Contin Educ Dent. 2011;32(3):44-49.
Clinical, Cosmetic and Investigational Dentistry

\section{Publish your work in this journal}

Clinical, Cosmetic and Investigational Dentistry is an international, peer-reviewed, open access, online journal focusing on the latest clinical and experimental research in dentistry with specific emphasis on cosmetic interventions. Innovative developments in dental materials, techniques and devices that improve outcomes and patient satisfac-

\section{Dovepress}

tion and preference will be highlighted. The manuscript management system is completely online and includes a very quick and fair peerreview system, which is all easy to use. Visit http://www.dovepress. com/testimonials.php to read real quotes from published authors. 